\title{
An Unusual Presentation of Pediatric Autoimmune Pancreatitis
}

\author{
David P. Galloway, MD¹, Daniel Wallihan, MD², Milton T. Smith, MD $^{3}$, and Maisam Abu-El- \\ Haija, MD ${ }^{1}$ \\ ${ }^{1}$ Division of Gastroenterology, Hepatology and Nutrition, Cincinnati Children's Hospital Medical \\ Center, Cincinnati, $\mathrm{OH}$ \\ ${ }^{2}$ Radiology Department, Cincinnati Children's Hospital Medical Center, Cincinnati, OH \\ ${ }^{3}$ Division of Gastroenterology, University of Cincinnati Medical Center, Cincinnati, $\mathrm{OH}$
}

\section{To The Editor}

Autoimmune pancreatitis (AIP) is a form of acute and chronic pancreatitis with an overall incidence described as up to $0.71-0.82$ per 100,000 persons. ${ }^{1,2}$ Two distinct phenotypes have been identified. ${ }^{3}$ Type 1 is more common in adult males and associated with serum IgG4 elevation and characteristic histological findings, whereas type 2 is more common in the pediatric population with a less frequent association with serum IgG4 elevation. ${ }^{1,3,4}$ No confirmed cases of type 1 AIP have been described in the pediatric population although there have been a few cases of probable type $1 \mathrm{AIP}^{4,5}$ We present a case of probable type 1 AIP in a child with a unique presentation of steatorrhea resulting from chronic pancreatitis.

\section{Case Presentation}

An 8-year old female presented to the outpatient clinic with a chief complaint of weight loss (11 lbs.; $17 \%$ of total body weight) and diarrhea over a four-month period. Diarrhea was described as "oily, yellow/orange" and foul smelling. There was a history of vague, intermittent abdominal pain but no prior episodes of documented acute pancreatitis.

Initial workup was revealing for amylase $46 \mathrm{u} / \mathrm{L}(<105 \mathrm{u} / \mathrm{L})$, lipase $40 \mathrm{u} / \mathrm{L}(48-199 \mathrm{u} / \mathrm{L})$, fecal elastase $15 \mathrm{mcg} / \mathrm{g}$ (> $201 \mathrm{mcg} / \mathrm{g})$, and sweat chloride $30 \mathrm{mEq} \mathrm{Cl} / \mathrm{L}(0-39 \mathrm{mEq} \mathrm{Cl} / \mathrm{L}$ for age range). Serum total $\mathrm{IgG}$ was elevated at $1400 \mathrm{mg} / \mathrm{dL}(598-1379 \mathrm{mg} / \mathrm{dL})$ with a serum IgG4 of $320 \mathrm{mg} / \mathrm{dL}$ ( $<189 \mathrm{mg} / \mathrm{dL}$ ). Direct endoscopic pancreatic function testing (ePFT) revealed insufficient levels of trypsin 5.9 and $7.4 \mathrm{~nm} / \mathrm{ml} / \mathrm{min}(>55.4 \mathrm{~nm} / \mathrm{ml} / \mathrm{min})$, amylase 8 and $9.8 \mathrm{um} / \mathrm{ml} / \mathrm{min}$ (>32 um/ml/min), lipase 7 and $4 \mathrm{um} / \mathrm{ml} / \mathrm{min}(>146 \mathrm{um} / \mathrm{ml} / \mathrm{min})$ and chymotrypsin 0.9 and $0.9 \mathrm{um} / \mathrm{ml} / \mathrm{min}(>2.5 \mathrm{um} / \mathrm{ml} / \mathrm{min})$ on two separate samples. Immunoreactive trypsinogen was $<1.2 \mathrm{ng} / \mathrm{mL}(10-57 \mathrm{ng} / \mathrm{mL})$. Gene sequence analysis of CFTR, PRSS1, SPINK1, and CTRC revealed that the patient was heterozygous for the

Corresponding Author: David Galloway, Division of Gastroenterology, Hepatology and Nutrition, Cincinnati Children's Hospital Medical Center, 3333 Burnet Avenue MLC 2010, Cincinnati, OH 45241, David.galloway @ cchmc.org. Telephone: (513) 636-4415. Fax: (513) 636-7804.

Conflict of Interest and financial disclosures: The authors of this manuscript do not have any conflicts of interest or financial disclosures to report. 
p.R1070Q pathogenic mutation in the CFTR gene. Magnetic resonance cholangiopancreatography (MRCP) was consistent with chronic pancreatitis with a small volume pancreas and residual low-grade inflammation throughout with emphasis on the body and tail. The pancreatic duct was collapsed and not seen. (Figure 1)

Endoscopic ultrasound (EUS) with pancreatic biopsy using fine needle aspiration (FNA) yielded tissue that was insufficient for analysis. Given the elevated IgG4 and imaging findings, a diagnosis of probable type 1 AIP was given. Patient was started on prednisone 20 $\mathrm{mg}$ daily $(0.7 \mathrm{mg} / \mathrm{kg} /$ day $)$ for three weeks followed by a taper over two months. Patient is currently asymptomatic more than six months since prednisone therapy with complete resolution of diarrhea and abdominal pain. She remains on supplemental pancreatic enzymes and is gaining weight. Total serum IgG and IgG4 have declined to $1030 \mathrm{mg} / \mathrm{dL}$ and 167 $\mathrm{mg} / \mathrm{dL}$, respectively. Repeat immunoreactive trypsinogen remains undetectable at $<1.2$ $\mathrm{ng} / \mathrm{mL}$ despite therapy.

\section{Discussion}

We describe a case of probable type 1 AIP in a child with a unique presentation. Most cases of type 1 AIP occur in adult males and present with obstructive jaundice. ${ }^{1,6}$ Additionally, organ involvement outside the pancreas is common with type 1 AIP and occurs in 50-70\% of cases. ${ }^{1}$ Our patient's presentation varied from these more commonly described features with an insidious onset of steatorrhea, vague abdominal pain and weight loss over several months without evidence for jaundice or other organ involvement.

According the ICDC for $\mathrm{AIP}^{3}$, our patient met criteria for probable type 1 AIP with atypical imaging findings of pancreatic parenchymal atrophy, level 2 serology and resolution of pain and IgG4 elevation after steroid course. To date, she does not have any other organ involvement.

Several studies have illustrated that serum IgG4 can be elevated in various conditions in addition to AIP to include IgG4-associated cholangitis, pancreatic cancer, benign pancreatic tumors and even in a normal pancreas. ${ }^{6,7}$ However, ranges for each of these entities differ. A serum IgG4 level of 135-140 mg/dL has a sensitivity of 76-95\% and a specificity of 86$97 \%$ for type 1 AIP. ${ }^{1,6,7}$ Specificity reached $99 \%$ in one study when a cutoff of $>280 \mathrm{mg} / \mathrm{dL}$ was implemented. ${ }^{6}$ Two cases of probable type 1 AIP in children have been described in the literature. ${ }^{5}$ Only one had documented serum IgG4 elevation to a level of $224 \mathrm{mg} / \mathrm{dL}$. Our patient presented with an initial serum IgG4 level of $320 \mathrm{mg} / \mathrm{dL}$, which is well above the thresholds discussed here and the highest reported level of serum IgG4 described in the pediatric autoimmune pancreatitis literature.

The CFTR gene mutation (p.R1070.Q, also known as c.3209G>A) found in our patient has been documented in the literature in subjects with pancreatic disease including chronic pancreatitis and likely is contributing to our patient's pancreatic dysfunction. 8,9

In conclusion, we have shared a case of probable type 1 AIP in an 8-year old child who presented with weight loss, steatorrhea and vague abdominal pain. Future studies in pediatric AIP are needed to further our understanding of this rare entity. 


\section{Acknowledgments}

There were no sources of funding or financial disclosures for this manuscript.

\section{References}

1. Zen Y, Bogdanos DP, Kawa S. Type 1 autoimmune pancreatitis. Orphanet J Rare Dis. 2011; 6:82. [PubMed: 22151922]

2. Nishimori I, Tamakoshi A, Otsuki M. Research Committee on Intractable Diseases of the Pancreas MoHL, Welfare of J. Prevalence of autoimmune pancreatitis in Japan from a nationwide survey in 2002. J Gastroenterol. 2007; 42(Suppl 18):6-8. [PubMed: 17520216]

3. Shimosegawa T, Chari ST, Frulloni L, et al. International consensus diagnostic criteria for autoimmune pancreatitis: guidelines of the International Association of Pancreatology. Pancreas. 2011; 40(3):352-358. [PubMed: 21412117]

4. Zen Y, Grammatikopoulos T, Hadzic N. Autoimmune pancreatitis in children: insights into the diagnostic challenge. J Pediatr Gastroenterol Nutr. 2014; 59(5):e42-e45. [PubMed: 25347159]

5. Friedlander J, Quiros JA, Morgan T, et al. Diagnosis of autoimmune pancreatitis vs neoplasms in children with pancreatic mass and biliary obstruction. Clin Gastroenterol Hepatol. 2012; 10(9): 1051-1055. [PubMed: 22732272]

6. Ghazale A, Chari ST, Smyrk TC, et al. Value of serum IgG4 in the diagnosis of autoimmune pancreatitis and in distinguishing it from pancreatic cancer. Am J Gastroenterol. 2007; 102(8):16461653. [PubMed: 17555461]

7. Dorn L, Finkenstedt A, Schranz M, et al. Immunoglobulin subclass 4 for the diagnosis of immunoglobulin subclass 4-associated diseases in an unselected liver and pancreas clinic population. HPB(Oxford). 2012; 14(2):122-125. [PubMed: 22221573]

8. Cohn JA, Friedman KJ, Noone PG, Knowles MR, Silverman LM, Jowell PS. Relation between mutations of the cystic fibrosis gene and idiopathic pancreatitis. N Engl J Med. 1998; 339(10):653658. [PubMed: 9725922]

9. Sharer N, Schwarz M, Malone G, et al. Mutations of the cystic fibrosis gene in patients with chronic pancreatitis. N Engl J Med. 1998; 339(10):645-652. [PubMed: 9725921] 


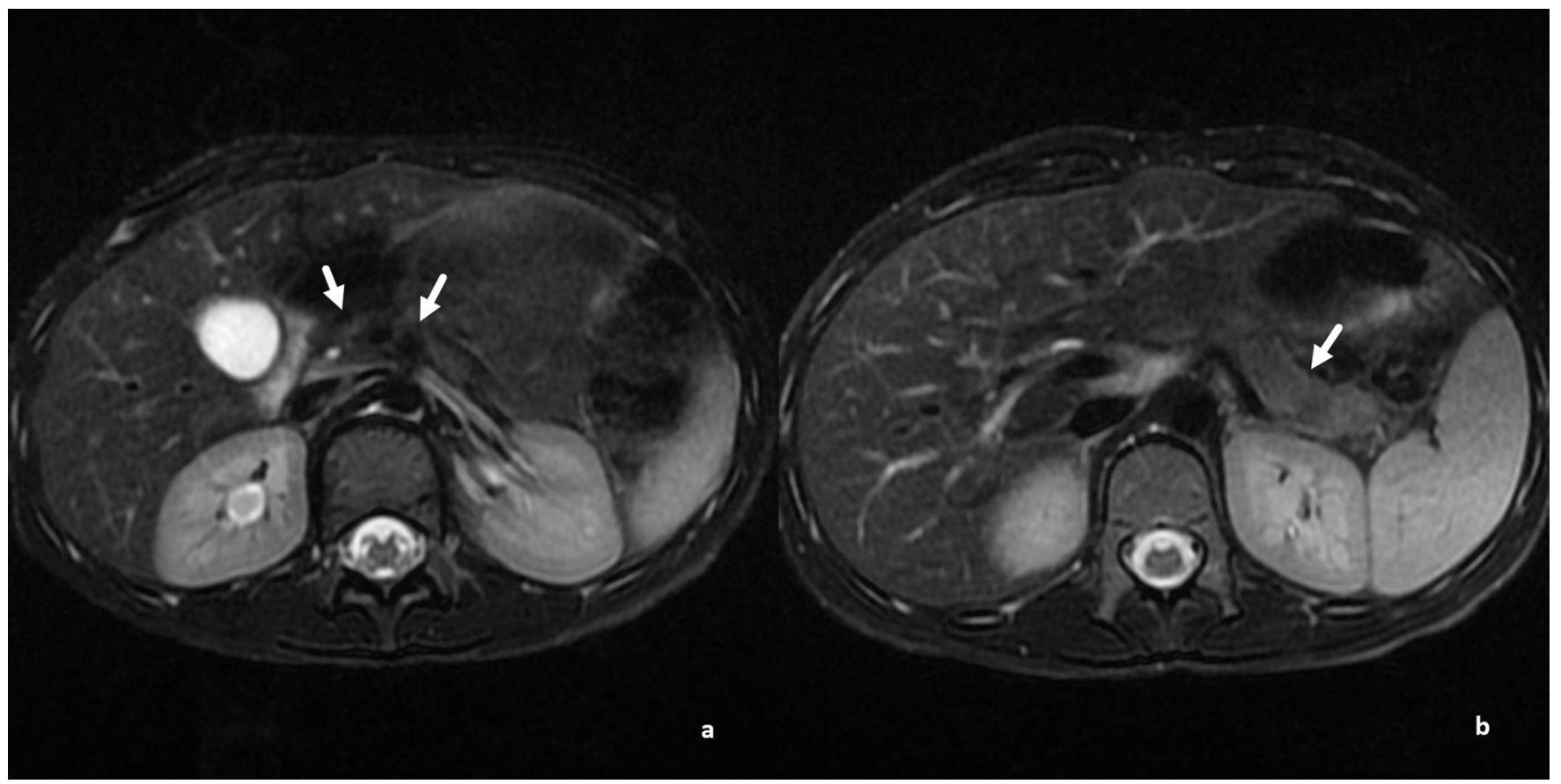

Figure 1.

MRCP axial T2 images of the pancreas. These are several axial T2 images of the pancreas with fat saturation demonstrating a heterogeneous signal, particularly at the body (a) and tail region (b). Overall pancreatic volume is decreased. The pancreatic duct is collapsed and not seen. 